\title{
Aktualisasi Nilai-Nilai Moderasi dalam Pandangan Islam
}

\author{
Zuhairi $^{1}$, Ahmad Bustomi ${ }^{* *}$ \\ ${ }^{1}$ Institut Agama Islam Negeri Metro, Indonesia \\ ${ }^{2}$ Institut Agama Islam Negeri Metro, Indonesia \\ ahmadbustomi@metrouniv.ac.id*
}

\begin{tabular}{cl}
\hline ARTICLE INFO & \multicolumn{1}{c}{ Abstract } \\
\cline { 2 - 3 } Article history: & This article aimed to explain how Muslims should implement their religion in a \\
Received & moderate manner in order to create a safe and peaceful life. This article is library \\
December 04, & research by focusing on library discourses which the sources were taken from the \\
2021 & journal article, books, and newspapers. According to the analysis, there were \\
Revised & several moderate values that Muslims should implement in their life in \\
December 14, & accordance to establish a peaceful life: Tawasuth which means taking a middle \\
2021 & way between right and left extreme; Tawazun which means balance between \\
Accepted & naqli and aqli, world-oriented and afterworld-oriented; and Tasamuh which \\
December 30, & means tolerance.
\end{tabular}
2021

Published by

Website

Keywords: Religious Moderation, Moderation Value, Islamic View.

This is an open access article under the CC BY SA license

Tapis : Jurnal Penelitian Ilmiah
http://e-journal.metrouniv.ac.id/index.php/tapis/index

https://creativecommons.org/licenses/by-sa/4.0/

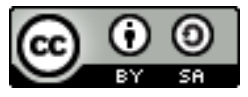

\section{PENDAHULUAN}

Satu dasawarsa sudah negeri ini digoncangkan dengan isu radikal. Lebih jauh isu ini berkembang biak setelah ditunggangi beberapa elit politik demi meraup suara banyak pada agenda pemilu. Isu tersebut mencapai puncak hingga muncul diksi-diksi yaitu cebong dan kampret. Kemudian muncul simbol yang mengarah pada ekstremis kanan yaitu kadrun. Sedikit menilik akar historisnya, banyak pengamat menyebutkan bahwa kemunculan fundamentalisradikal tidak bisa dilepaskan dari pengaruh keagamaan dan politik Timur Tengah ke Indonesia (Syukur, Januari 2012).

Istilah kadrun merupakan singkatan dari kadal gurun identic dengan arab yang kebanyakan memiliki gurun. Diksi kadrun dikaitkan dengan paham radikal pada 2019 yang mana hal ini tentunya menjadi tontonan masyarakat Indonesia yang notabene tentu saja tidak semua orang mampu memfilternya sehingga mereka tidak mampu menempatkan diri ataupun membedakan situsi dan kondisi yang tepat dimana mereka dapat menggunakan istilah tersebut di dalam kehidupan sosial.

Anak-anak yang notabene belum memiliki daya saring yang baik tidak perlu ikut-ikutan mendengar atau membaca diksi yang sebenarnya hanya lahir dari konflik politik dua kubu. Perlunya rem dari orang tua agar diksi negatif tidak didengar oleh anak-anak sebenarnya juga perlu dilakukan oleh media yang pada dasarnya mudah diakses juga oleh anak-anak. Tentu saja hal tersebut tidak berlaku di media yang tujuannya adalah keuntungan atau uang. Paham radikal merupakan bibit bagi gerakan terorisme sebagaimana peristiwa yang terjadi di Malaysia pada 2016 lalu, dimana seorang bernama Moch. Rafi memberikan statement yang mengejutkan terhadap masyarakat Islam di Malaysia. "bunuhlah mereka dimana saja mereka berada. Bahkan Jika anda di kereta gunakan senjata dan pisau untuk tikam dada mereka". Ia juga memberikan pernyataan kepada polisi Malaysia bahwa "rekan mereka akan memburu Anda (polisi Malaysia) habis-habisan" (Ashari, Desember 2019). Islam Radikal sebagai diksi awal (sebelum kadrun) sepatutnya diobati dengan membumikan istilah Islam moderat yang tentunya 
dengan menebar benih-benih kebaikan secara praksis maupun teoritis. Pendidikan pemahaman agama yang moderat semcam ini juga saat ini mulai menyebar di Universitas (Imam Mustofa, 2019) maupun di sekolah (Busyro, 2019).

Banyak penelitian yang mengkaji tentang moderasi beragama diantaranya (Jumala, 2019) yang menyebutkan bahwa Seorang muslim dapat menempati tujuh tingkatan spiritualitas manusia dari yang bersifat egois sampai yang suci menurut perintah Allah. Tingkatan itu terdiri dari nafsu al-amarah, nafsu al-lawwōmah, nafsu al-mulhimma, nafsu al-muța'innah, nafsu arradiyah, nafsu al-mardiah dan nafsu as-safiyah. Kemudian penelitian yan dilakukan oleh Nunu Burhanuddin (Nunu Burhanuddin, 2019), Mohd Roslan Mohd Nor (Ibrahim, 2020), yang lebih fokus kepada konflict terkait agama, di sisi lain hampir senada dengan tulisan tersebut, Abdullah (Thoyibi, 2020) lebih fokus kepada kekerasan dalam praktik agama. Selanjutnya penelitian dengan judul Moderate Islam and the social construction of multi-ethnic communities in the hinterland of West Kalimantan (Prasojo, 2019) yang ditulis berdasarkan kajian lapangan. Berbeda dengan penelitian sebelumnya, penelitian ini fokus pada nilai-nilai moderasi Islam melalui kajian Pustaka sebagai upaya menekan konflik atau kekerasan antar agama.

Tulisan ini hadir sebagai salah satu upaya menebar benih pemahaman penerapan Islam yang moderat dalam tataran teoritis sebagai salah satu upaya mengerem prilaku radikalime. Di dalam studi ini peneliti akan memaparkan tentang bagaimanakah implementasi sebagai seorang muslim moderat dalam bersikap dan berfikir sebagai warga negara yang baik. Di samping itu, agar menjadi pelajaran tentang bagaimana bersikap jeli, rinci dan bijak di dalam dunia maya agar tidak menjadi golongan clicktivism (alfitri, 2019).

\section{METODE}

Tulisan ini termasuk ke dalam penelitian pustaka, yang berfokus pada kajian-kajian kepustakaan karena sumber-sumber penelitian diambil dari artikel jurnal, buku-buku, hasil penelitian dan surat kabar. Metode pengumpulan data menggunakan metode interpretatif deskriptif yang akan menjelaskan dan menggambarkan objek kajian. Sumber data yang dikumpulkan adalah berupa informasi atau data empirik yang bersumber dari buku-buku, jurnal, hasil laporan penelitian dan literatur lain yang mendukung tema penelitian ini.

Sumber data primer adalah sumber data pokok yang langsung dikumpulkan peneliti dari objek penelitian, yaitu: buku/artikel yang menjadi objek penelitian. Data primer juga diperoleh langsung dari tokoh (penulis) jika tokoh tersebut masih hidup (Harahap, 2014). Instrumen pada penelitian studi kepustakaan adalah peneliti sendiri (human instrument). Peneliti berperan sebagai perencana, pelaksana pengumpulan data, analisis, penafsir data, dan pada akhirnya ia menjadi pelapor hasil penelitiannya (Yaniawati, 2020).

\section{HASIL DAN PEMBAHASAN}

\section{Moderasi Islam}

Islam moderat atau yang dimaksud juga Islam Wasathiyyah, berasal dari dua kata yaitu Islam dan "wasathiyyah". Islam sebagaimana yang diketahui adalah agama yang penuh dengan keberkahan yang dibawa oleh Nabi Muhammad SAW (Fahri, 2019). Islam merupakan agama mayoritas yang ada di Indonesia bahkan negara dengan pemeluk agama Islam terbanyak di dunia.

Moderasi beragama merupakan satu ajaran yang kokoh dalam Islam sebagaimana telah terlihat baik secara tekstual dan kontekstual dilakukan oleh Nabi Muhammad SAW (Yusnawati, 2021). Kata moderat dalam bahasa Arab dikenal dengan al-wasathiyah sebagaimana terekam dari QS. Al-Baqarah (2) ayat ke-143.

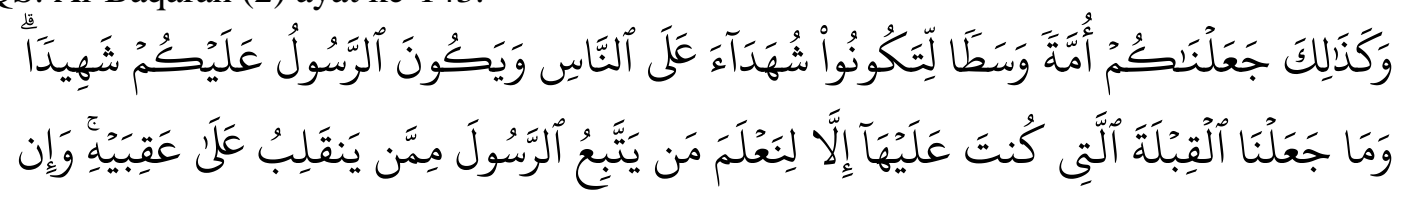




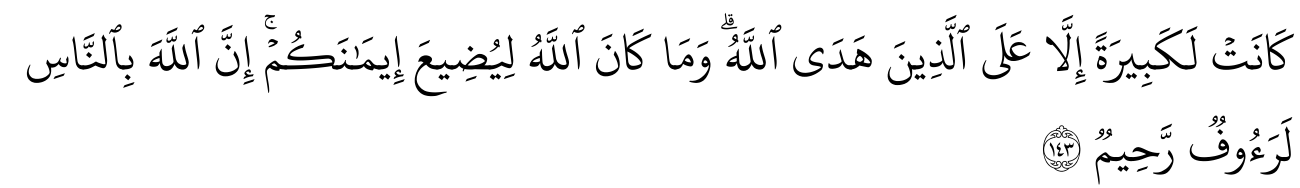

Dan demikian (pula) Kami telah menjadikan kamu (umat Islam), umat yang adil dan pilihan agar kamu menjadi saksi atas (perbuatan) manusia dan agar Rasul (Muhammad) menjadi saksi atas (perbuatan) kamu. Dan Kami tidak menetapkan kiblat yang menjadi kiblatmu (sekarang) melainkan agar Kami mengetahui (supaya nyata) siapa yang mengikuti Rasul dan siapa yang membelot. Dan sungguh (pemindahan kiblat) itu terasa amat berat, kecuali bagi orang-orang yang telah diberi petunjuk oleh Allah; dan Allah tidak akan menyia-nyiakan imanmu. Sesungguhnya Allah Maha Pengasih lagi Maha Penyayang kepada manusia.

Kata al-Wasath (وََّّ disebutkan bahwa sebaik-baik persoalan adalah yang berada di tengah-tengah (Akhmadi, 2019). Moderat dalam pemikiran Islam adalah mengedepankan sikap toleran dalam perbedaan, keterbukaan menerima keberagamaan (inklusivisme), baik perbedaan dalam mazhab maupun agama. Perbedaan tidak menghalangi untuk menjalin kerja sama, dengan asas kemanusiaan (Darlis, 2017). Memiliki keyakinan bahwa agama Islam yang paling benar, tidak memiliki arti harus melecehkan agama orang lain. Sehingga akan terjadilah persaudaraan dan persatuan antar umar beragama, sebagaimana yang pernah terjadi di Madinah di bawah komando Rasulullah SAW. Lebih jauh keyakinan bahwa pemahaman kegamaannya yang paling benar, juga tidak kemudian meligitimasi prilakunya untuk menyalahkan, menyesatkan atau mengkafirkan pemahaman keagamaan orang lain.

Adapun pengertian secara terminologis al-wasthiyah (moderat) adalah suatu metode berfikir, berinteraksi dan bersikap yang dilandasi atas sikap tawazun (balance/seimbang) dalam menyikapi dua keadaan perilaku yang dimungkinkan untuk dianalisis dan dibandingkan, sehingga dapat ditemukan sikap yang sesuai dengan kondisi dan tidak bertentangan dengan nilai-nilai ajaran agama dan tradisi masyarakat (Hanafi, 2009). Berdasarkan pengertian ini, sikap moderat/wasathiyah akan memungkinkan seseorang untuk tidak hanya mengandalkan dalil naqli saja atau dalil 'aqli saja serta melindungi seseorang dari kecenderungan sikap yang berlebihan yang cenderung berat sebelah baik ekstrim kanan (radikalisme) ataupun esktrim kiri (liberalisme).

Pengertian terminologis moderasi (al-wasthiyah) sebagaimana dikemukakan oleh Yusuf Qardhawi di dalam buku Khasais al-Ammah li Al-Islam, menyatakan bahwa moderasi dengan ungkapan yang sama yakni al-tawasuth atau al-tawazun yakni suatu upaya menjaga keseimbangan antara dua sisi/ujung/ pinggir yang berlawaanan atau yang bertolak belakang, agar tidak ada yang saling mendominasi dan menegaskan yang lain (Qardhawi, 1983).

Pengarustamaan moderasi pada akhirnya mendapat perhatian khusus dari pemerintah. Aturan ini terkait penggunaan pakaian seragam dan atribut agama bagi peserta didik, pendidik dan tenaga kependidikan di lingkungan sekolah dasar sampai menengah negeri, yang ditandatangani oleh Menteri Pendidikan dan Kebudayaan Nadiem Makarim, Menteri Dalam Negeri Tito Karnavian, dan Menteri Agama Yaqut Cholil Qoumas, (Nasution, 2021). Hal ini muncul tidak lepas dari mulai merebaknya prilaku intoleran di Indonesia. Dalam artikel berjudul Internalisasi Nilai-nilai Moderasi Beragama dalam Pembelajaran PAI di SMA Al-Biruni Cerdas Mulia Kota Bandung disebutkan bahwa awal mula munculnya gagasan moderasi beragama ialah disebabkan munculnya prilaku-prilaku intoleran dalam beragama dimana sebagian orang dengan mengatasnamakan agama melakukan kekerasan terhadap agama dan kelompok lainnya, (Gunawan, 2021).

\section{Aktualisasi Nilai-Nilai Moderasi Islam}

Nilai dalam bahasa Inggris di sebut value yang secarara bahasa berarti harga, (Anthony Giddens, 1995). Nilai merupakan konsep yang menunjukkan pada segala sesuatu yang dianggap 
berharga dalam kehidupan manusia, yaitu tentang sesuatu yang dianggap benar, baik, layak, indah, pantas, penting, dan dikehendaki oleh manusia dalam kehidupannya, (Abidin, 2021). Maka berbanding terbalik dari itu, tidak bernilai memiliki makna tidak benar, tidak baik, tidak layak, tidak pantas, tidak indah, tidak penting dan tidak dikehendaki oleh seseorang dalam dirinya. Ada beberapa poin yang menjadi nilai utama dari moderasi beragama menurut Islam dan itu sangat perlu sekali dikembangkan dan diajarkan kepada anak-anak sejak dini. Hal ini tentu saja juga selain karena menguatnya isu radikalisme ditambah dengan fakta bahwa Negara kesatuan Republik Indonesia dibangun oleh sekian banyak agama dan kepercayaan, suku-suku yang begitu heterogen, bahasa yang begitu banyak serta adat istiadat yang berbeda antar daerah. Nilai-nilai moderasi beragama dalam Islam diantaranya adalah tawasut, tasamuh dan tawazun dengan pengaktualisasian sebagai berikut:

\section{Tawasuth}

Tawasuth diartikan sebagai upaya mengambil jalan tengah dari dua kelompok ekstrem, yaitu ekstrem kanan dan ekstrem kiri. Ekstrem kanan yang sering dimaknai sebagai kaum berpaham radikalisme dan ekstrem kiri yang kemudian disebut sebagai berpaham liberal.

Ekstrem kanan yang cenderung kurang menerima proses berfikir dalam memahami agama, dan mengembalikan segala sesuatunya sebagaimana kelahiran Islam di Timur tengah dalam hal ini masa Makkah dan Madinah. Lantas secara ekstrem ingin mengembalikan arah segala aspek, termasuk aspek bernegara dan sebagai warga negara mengambil contoh langsung Rasulullah dengan dalih Islam sebagai agama yang sempurna mampu mewadahi segala aspek kehidupan ummat manusia termasuk dalam konsep pemerintahan.

Kelompok ini cenderung ingin merubah segala aspek bernegara menjadi berasaskan Islam berikut semua ornamen-ornamennya meskipun dengan cara kekerasan. Penusukan terhadap pejabat pemerintah, penyerangan terhadap polisi, pembunuhan kepada tentara, bom bunuh diri menjadi sebuah ajang ibadah bahkan jihad bagai mereka. Hal ini tentunya bukan menjadi tujuan utama diutusnya Nabi Muhammad yang diutus tidak lain hanya untuk menyempurnakan akhlak. Kasus-kasus kekerasan yang kian meningkat dan membesar tersebut telah menjadi konsen global (Khasan, 2021), yang harus segera ditangani. Lebih jauh parahnya lagi, golongan tersebut cepat tumbuh melalui media sosial yang notabene lebih banyak diakses masyarakat luas ketimbang dua organisasi Islam moderat, (Akmaliah, 2020).

Di sisi ekstrem kiri, orang-orang cenderung menyepelekan nash baik Al-Qur'an maupun Hadits. Terlalu mengedepankan akal dan memiliki kecenderungan untuk menafsirkan agama sebebas-bebasnya tanpa ada barometer yang jelas. Ajaran yang terkenal dari golongan ini diantaranya adalah keyakinan bahwa Al-Qur'an sebagai makhluk, serta dalam konteks Qada dan Qadar disebutkan bahwa manusia sendirilah yang menciptakan perbuatannya

Al-Qur'an dianggap sebagai makhluk bagi mereka dan Taqdir murni merupakan hasil dari jerih payah manusia. Golongan mutazilah menjadi model utama dalam kajian-kajian muslim yang kemudian secara ekstrem terlalu mengedepankan akal. Lahirnya liberalisme sebagai gaya baru ekstrem ini justru dipandang sudah mulai menyepelekan agama bahkan cenderung kepada ingkar sunnah.

Oleh karena itu, ajaran Islam yang tawasuth hadir diharapkan agar mampu mewadahi keduanya, dalam artian penggunaan akal diakui sedangkan nash juga tetap menjadi pegangan utama ummat Islam.

\section{Tawazun}

Tawazun (seimbang) artinya mampu menyeimbangkan antara dalil aqli dan dalil naqli dan antara kehidupan duniawi dan rohani. Kecenderungan untuk secara frontal membabi buta berpegang pada dalil aqli akan mengakibatkan manusia menyepelekan wahyu (Al-Qur'an dan hadits) sedangkan jika hanya berpatokan pada dalil naqli maka manusia akan cenderung melupakan dunia.

Di dalam ajaran Islam dan keberagamaan umat Islam ada prilaku-prilaku yang ditengarai menjadi pemantik kemunduran umat Islam sendiri yang terindikasikan karena tidak 
mengamalkan sikap tawazun ini. Banyak orang-orang yang keluar dari gerakan horisontal menuju gerakan vertikal yang keluar dari kehidupan dunia dan menghabiskan waktunya untuk bermunajat kepad allah SWT (untuk kepentingan akhirat semata). Di dalam ajaran Islam yang moderat tentunya bukanlah hal yang demikian itu karena mementingkan satu kehidupan lain lantas mengorbankan kepentingan kehidupan lainnya yang notabene sama pentingnya. Padahal menyelamatkan diri tanpa yang lain adalah perbuatan destruktif dan naif. (Shimogaki, 2007).

Prilaku sufi yang kemudian seperti buah simalakama atau senjata makan tuan, dimana kemiskinan, kelaparan dan ketakutan merupakan suatu kondisi yang harus diperhatikan. Bersabar dalam penindasan dan penjajahan dipandang sebagai suatu amal yang berpahala besar dan dipandang akan menimbulkan kebahagiaan sendiri yang mengantarkan kepada kebahagiaan sejati di akhirat kelak. Tawakkal telah membuat muslim berhenti berjuang dan lupa mempersiapkan masa depan.

Hal ini juga pada ahirnya menjadi faktor penyebab ketidakseimbangan hidup di dunia. Di sisi lain ada yang terlalu fokus ke arah vertikal hingga lupa membumi, lupa tugasnya sebagai kepala rumah tangga yang memiliki anak yang harus di beri pendidikan, lupa dengan tetangga yang sebagai makhluk sosial perlu berinteraksi. Sedangkan disebrang lainnya ada yang hanya berfokus masalah horisontal yang mengarustamakan kehidupan duniawi. Berlomba-lomba mencari kekayaan, ketenaran, kekuasaan dan nafsu-nafsu dunia lainnya hingga lupa bahwa kelak akan kembali kepada sang penciptanya.

Oleh karena itu, sikap seimbang di dunia dan akhirat sangat dibutuhkan sesuai dengan kadarnya masing-masing. Tiap-tiap pribadi memiliki tugasnya masing-masing, pemimpin negara menjalankan tugasnya sebagai kepala negara, pengacara menjalankan tugasnya sebagai pengacara, petani menjalankan tuganya sebagai petani dan seterusnya.

\section{Tasamuh}

Tasamuh (toleran) memiliki arti mengakui perbedaan dalam berbagai aspek, khususnya aspek keagamaan, (Maimun dan kosim, 2019). Tasamuh tidak hanya mengakui perbedaan agama tetapi mengakui adanya perbedaan pemahaman dalam satu agama. Lebih jelas sebenarnya sudah termaktub dalam firman-Nya pada Qs. AL-Baqarah ayat 256:

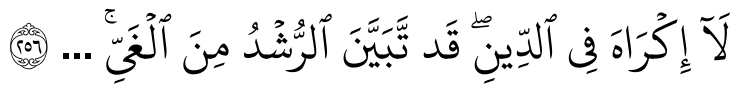

Tidak ada paksaan untuk (memasuki) agama (Islam); sesungguhnya telah jelas jalan yang benar daripada jalan yang sesat.

Meski mempunyai power kekuasaan yang tiada tara Allah SWT tidak memaksakan manusia untuk mengikuti ajaran-ajaran-Nya. Islam mengajarkan jelas dalam wahyunya tentang tidak adanya paksaan bagi mereka yang ingin mengikuti ajaran Islam. Hal ini berarti bahwa prilaku memaksa berbuat baik atau memaksa meninggalkan ketidak baikan yang acap kali dipertontonkan oleh banyak oknum muslim atau oknum organisasi masyarakat Islam di Indonesia sama sekali tidak bisa dibenarkan. Prilaku tasamuh juga dibatasi oleh ibadah mahdod sebagaimana hal ini juga pernah dikisahkan dalam banyak kitab-kitab sirah nabawiyah terutama terkait asbabun nuzulnya surah Al-Kafirun. Manusia harus tetap menjalin kerukunan, saling mendukung, tolong menolong, mengamankan, berkolaborasi, dan berkompromi namun pada ranah ibadah harus tetap dilakukan sesuai dengan agama dan kepercayaan masing-masing.

Tasamuh menjadi sebuah keniscayaan untuk secara masif diimplementasikan di Indonesia yang multi etnis, multi bahasa, multi budaya, multi agama. Fenomena maraknya oknum yang mengatasnamakan agama dan melakukan kekerasan pada dasarnya belum selesai memahami konsep hidayah yang mutlak milik Allah SWT. Hidayah secara umum diasosiasikan kepada seseorang yang berpindah dari agama lain ke agama Islam (mualaf) atau terkait konsep penyesalan/taubat (tawbah). Taubat disebut sebagai satu perasaan penyesalan yang mendalam terhadap dosa-dosa yang pernah dilakukan, dan bertekat untuk kembali pada Allah dengan niat untuk mematuhinya, (Suhartini, 2020). Hidayah pada dasarnya merupakan suatu dinamika personal yang berkaitan langsung antara si pelaku dengan Tuhan. 
Penjelasan diatas merupakan tiga nilai ajaran moderasi beragama dalam Islam, yaitu pertengahan, seimbang dan toleran. Ketiga nilai tersebut harus menjadi landasan dasar dalam mengimplementasikan ajaran agama ditengan perbedaan masyarakat demi terciptanya kehidupan bernegara yang rukun dan damai.

\section{KESIMPULAN}

Nilai-nilai moderasi agama dalam Islam sejatinya terdiri dari tiga hal yaitu Tawasuth (mengambil jalan tengah dari dua kutub ekstrem yaitu ekstrem kanan dan ekstrem kiri), Tawazun (seimbang antara dalil naqli dan dalil aqli serta antara kehidupan duniawi dan kehidupan rohani), dan Tasamuh (toleran antara perbedaan agama dan perbedaan pemahaman agama). Dengan ketiga nilai tersebut diharapkan manusia dapat menyelaraskan kehidupannya sebagai individu, anggota keluarga, anggota masyarakat dan sebagai warga negara yang baik.

\section{UCAPAN TERIMA KASIH}

Terima kasih penulis sampaikan kepada pihak-pihak yang terlibat dalam penulisan ini yaitu Ahmad Bustomi sebagai penulis kedua dan para editor.

\section{PERNYATAAN KONTRIBUSI PENULIS}

Artikel ini ditulis oleh Zuhairi sebagai penulis pertama dan Ahmad Bustomi sebagai penulis kedua.

\section{REFERENSI}

Akhmadi, Agus. (2019). Moderasi Beragama dalam Keragaman Indonesia, Jurnal Diklat Keagamaan: 49.

Ahyar, Muzayyin and Alfitri, (2019). Aksi Bela Islam: islamic clicktivism and the new authority of religious propaganda in the millennial age inIndonesia, Indonesian Journal of Islam and Muslim Societies Volume 9, no.1: 1.

Akmaliah, Wahyudi. (2020). The Demise Of Moderate Islam: New Media, Contestation, And Reclaiming Religious Authorities. Indonesian Journal of Islam and Muslim Societies Vol. 10, no. 1: 1-2.

Aly, Abdullah and Muhammad Thoyibi. (2020). Violence In Online Media And Its Implication To Islamic Education Of Indonesia. Indonesian Journal of Islam and Muslim Societies Vol. 10, no. 1: 177.

Asharai, Haikal. (2021). Radikalisme dan Fundamentalisme dalam Islam: Sejarah, Paham dan Gerakannya serta Tafsir atas Ayat-Ayat Perang. Intizar. Volume 25, No. 2: 102.

Ashari, Haikal. (2009). Radikalisme dan Fundamentalisme Dalam Islam. Intizar: 102.

Burhanuddin, Nunu. Ahmad Ali Nurdin, Muhammad Irfan Helmy. (2019). Religious Conflict And Regional Autonomy In Church Establishment And Islamic Clothing In West Pasaman And Dharmasraya. Indonesian Journal of Islam and Muslim Societies, Vol. 9, no. 2: 189.

Darlis. (2017). Mengusung Moderasi Islam di Tengah Masyarakat Multikultural. Rausyan Fikr: 225.

Fahri, Mohammad, dan Ahmad Zainuri. (2019). Moderasi Beragama di Indonesia. Intizar: 2478. 
Faldiansyah, Iqram. (2019). Menghadiri Perayaan Hari Besar Agama Non Islam Perspektif Al Qur'an. Tawshiyah. Volume 14, No. 2: 63.

Febriandi, Yogi and Yaser Amri. (2021). Stuck In Sharia Space, The Experiences Of Christian Students In Langsa, Aceh. Al-Jāmi`Ah: Journal Of Islamic Studies. Vol. 59, no. 1: 33.

Feriyanto. (2020). Tarekat Dan Moderasi Beragama. Jurnal Diklat Keagamaan: 158.

Gidden, Anthony. (1995). Politics, Sociology and Social Theory: Encounters with Classical. Cambridge: Polity.

Gunawan, Heri, Mahlil Nurul Ihsan dan Encep Supriatin Jaya. (2021). Internalisasi Nilai-nilai Moderasi Beragama. Atthulab: 14.

Hanafi. (2009). Konsep Al-Wasthiyah dalam Islam. Harmoni Jurnal Multikultural dan Multireligious: 40.

Harahap, Nursapia. (2014). Penelitian Kepustakaan. IAIN-SU Medan: 71.

Ibrahim, Mohd Roslan Mohd Nor and Muhammad Khalis. (2020). Conflicts Of Religious Education In A Secular State: A Study On Turkey's Imam-Hatip School. Qudus International Journal of Islamic Studies (QIJIS) Volume 8, Number 1: 107.

Jumala, Irwani. (2019). Moderasi Berfikir untuk Menempati Tingkatan Spiritual Tertinggi dalam Beragama. Substantia: 170.

Junika, Hesty. (2020). Analisis Berita Politik Jelang Pemilihan presiden Republik Indonesia Tahun 2019 pada Surat Kabar. JOM FISIP Volume 7: 06.

Kazuo, Shimogaki. (2007). Kiri Islam, antara Modernisme dan Postmodernisme. Yogyakarta. LkiS: 128.

Khasan, Moh. (2021). From Textuality To Universality The Evolution Of Hirābah Crimes In Islamic. Al-Jāmi‘ah: Journal of Islamic Studies Vol. 59, no. 1: 1.

Imam Mustofa, Dedi Irwansyah, Mukhtar Hadi dan Enizar. (2019). Reading Types Of Islamic Fundamentalism. Qijis: Qudus International Journal of Islamic Studies Volume 7, Number 2, 2019: 268.

Maimun dan Mohammad Kosim. (2019). Moderasi Islam di Indonesia. Yogyakarta: LKiS: 32.

Nasution, Nadya Amalia dan Umi Rojiati. (2021). Moderasi Beragama Dalam Ruang Digital: Gerakan Opini Digital SKB 3 Menteri. Jurnal Diklat Keagamaan: 11.

Qardawi. (1983). Al-Khosois al-Amah Li Al-Islam diterjemahkan Rofi Munawar, Surabaya: Risalah Gusti.

Qomaruzzaman, Bambang and Busyro. (2019). Ricoeur Hermeneutic Reading On Tariq Ramadan's Thoughts For The Formulations Of The Tolerant Islamic Educational Theology. QIJIS: Qudus International Journal of Islamic Studies Volume 7, No. 2: 204. 
Prasojo. Zaenuddin Hudi, Elmansyah and Muhammed Sahrin bin Haji Masri. (2019). Moderate Islam And The Social Construction Of Multi-Ethnic Communities In The Hinterland Of West Kalimantan. Indonesian Journal of Islam and Muslim Societies Vol. 9, no. 2: 218.

Suhartini, Rr. (2020). Hidayah As A Social Reality The Dynamics Of Religiosity Among Muslim Professionals In Surabaya. JOURNAL OF INDONESIAN ISLAM Volume 14, Number 01: 249.

Syukur, Suparman. (2012). Islam Radikal vs Islam Rahmah. Teologia. Volume 23, No. 1: 91.

Yaniawati, R. Poppy. (2020). Penelitian studi kepustakaan (library research), disajikan pada acara "Penyamaan Persepsi Penelitian Studi Kepustakaan" di Lingkungan Dosen FKIP Unpas. 14 April (2020): 23.

Yusnawati dkk. (2021). Internalisasi Nilai-nilai Mderasi Beragama. Jurnal Diklat Keagamaan: 1.

\section{Copyright Holder :}

(C) Zuhairi., \& Bustomi, A., (2021).

First Publication Right :

(C) Tapis : Jurnal Penelitian Ilmiah

This article is under:

CC BY SA 